Año LXXXI. urtea $276-2020$ Enero-abril Urtarrila-apirila

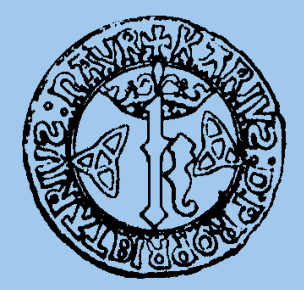

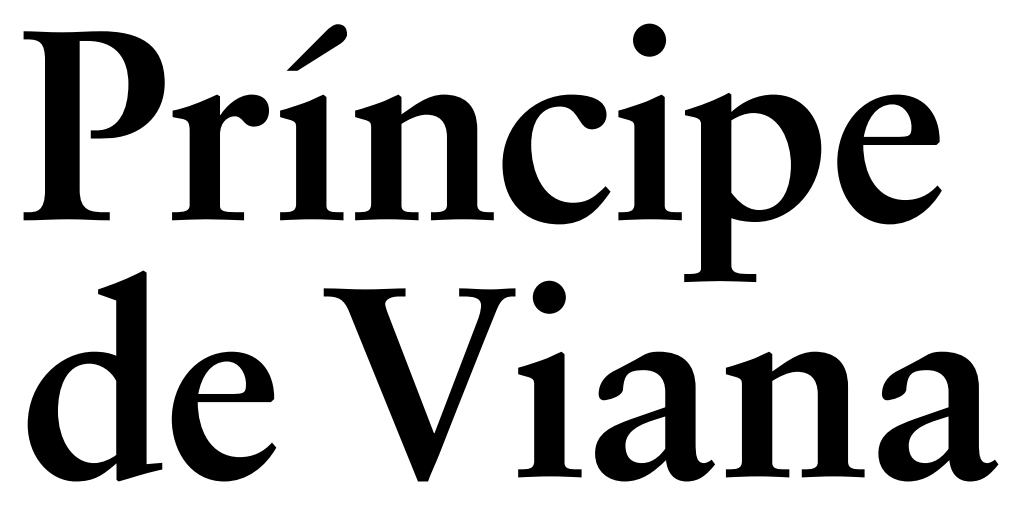

SEPARATA

\section{Tensión de rotura.}

Un panorama expositivo de 2019

Mireya Martín Larumbe 


\section{Sumario / Aurkibidea}

\section{Príncipe de Viana}

Año LXXXI • n. ${ }^{\circ} 276$ • enero-abril de 2020

LXXXI. urtea $\cdot 276$. zk. 2020 ko urtarrila-apirila

\section{LITERATURA}

La realidad literaturizada y la ira contra la religión católica y el obispo de Pamplona en el «Libro segundo» de La familia de Errotacho, de Pío Baroja Miguel Ángel García de Juan

\section{HISTORIA}

La represión del protestantismo en el tribunal inquisitorial de Calahorra-Logroño (1550-1610)

Marcos Gómez García

Entre España y México, la libertad. El embajador Félix Gordón Ordás y su evocación de la figura del navarro Javier Mina en el marco de la guerra civil española

Un discurso inédito de Víctor Sainz de Robles en 1867

Emilio Cervantes Ruiz de la Torre

Política social y autogobierno en el núcleo de la conspiración carlista antirrepublicana

La botica del monasterio cisterciense de Santa María de La Oliva (Navarra) Juan Manuel Garde Garde

\section{DERECHO / ZUZENBIDEA}

Un debate sobre la Ley de 1841: Navascués, la Diputación, «El Mosquerino» y Ezquerra 


\section{Sumario / Aurkibidea}

\section{LOS TRABAJOS Y LOS DÍAS DEL AÑO 2019 / 2019ko LANAK ETA EGUNAK}

Tesis doctorales sobre temática navarra de ciencias humanas, sociales y jurídicas, leídas en 2019

(Según la Base de datos Teseo del Ministerio de Educación)

Medio siglo de Fontes Linguae Vasconum

Ekaitz Santazilia

Actividades en torno al cincuenta aniversario de la revista Cuadernos de

Etnología y Etnografía de Navarra

David Mariezkurrena

Autores y autoras navarras en castellano, año 2019

Mikel Zuza Viniegra

Nafar egileen euskarazko liburuak 2019an

Ángel Erro Jiménez

Viento a favor: talento y carácter. Navarra en la industria audiovisual (2019)

Marga Gutiérrez Díez

Tensión de rotura. Un panorama expositivo de 2019

Mireya Martín Larumbe

Hiriartea: crónica de un proyecto frustrado por una mala práctica en las políticas culturales

Arantza Santesteban

De escalas, tiempos y cultura: grado en Historia y Patrimonio por la UPNA

Fernando Mendiola Gonzalo, Miguel R. Wilhelmi

Investigación y difusión del patrimonio cultural navarro en la Universidad de

Navarra (2019)

Yolanda Cagigas Ocejo

Entrevista a Tomás Yerro Villanueva. Premio Príncipe de Viana de la Cultura 2019

Alicia Ezker Calvo

Si mi padre volviera, yo sería su escudero. Qué gran caballero era

Tomás Yerro. (Discurso)

Currículums

Analytic Summary

Normas para la presentación de originales / Idazlanak aurkezteko arauak /

Rules for the submission of originals

6 Príncipe de Viana (PV), 276, urtarrila-apirila, 2020 ISSN: 0032-8472 | ISSN-e: 2530-5824 | ISSN-L: 0032-8472 


\title{
Tensión de rotura. Un panorama expositivo de 2019
}

\author{
Mireya MARTÍn LARUMBE \\ Artista visual. Mediadora experta en Género y Arte Contemporáneo \\ mireya@mireyamartinlarumbe.com
}

DOI: https://doi.org/10.35462/pv.276.14

Me dispongo a escribir este artículo en el que, desde una mirada y posicionamiento personal, abordaré el panorama expositivo del pasado año 2019 en Navarra, sin dejar de preguntarme por el que será este mismo artículo a un año vista, en 2020, con las consecuencias de la crisis de la epidemia del COVID-19 que ya se sienten en el sector del arte. Con esta incertidumbre y prefigurando una debacle que ya empieza a constatarse, hablaré a continuación de una serie de propuestas expositivas de diversa índole y titularidad, cuyas únicas características comunes son la Comunidad Foral (aunque enmarcadas en su mayoría en Pamplona) como lugar, y el arte contemporáneo y sus particularidades como génesis. Dedicaré después unas líneas a lo que la pandemia ha puesto de manifiesto de la forma más descarnada posible: las consecuencias derivadas de la falta de atención política y la sistemática falta de trato profesional dada a este sector imprescindible.

2019 ha sido un año que, si bien inicialmente no parecía presentar grandes cambios ni novedades en el reducido contexto de la creación artística en Navarra, finalmente ha resultado rupturista, marcando el que podría ser el inicio de una época de cambio drástico en la manera de entender y gestionar el arte contemporáneo y su importancia dentro de nuestra comunidad.

Empezaré el trazado de este panorama expositivo haciendo un brevísimo repaso por algunas exposiciones y eventos de carácter continuista, iniciativas ya puestas en marcha en años anteriores que van asentándose, cuando no lo están ya, en lo que podríamos denominar el circuito del arte en Navarra. Este es el caso de «948 Merkatua. Mercado de las Artes de Navarra y foro de encuentros profesional», evento en el que no me detendré demasiado precisamente por tratase de una iniciativa dedicada a las industrias 
culturales y no tanto al arte. Sin embargo, hay algo que considero esencial destacar aquí: la diferencia entre industrias culturales y creativas ${ }^{1}$ y creación artística. La creación artística no es una industria cultural en sí misma sino su origen. Teniendo esto en cuenta, aplicar políticas propias de las industrias culturales a los y las creadoras sin atender a la propia naturaleza del acto de creación es contraproducente, pues lo falsea convirtiéndolo en algo mercantilista. Que el arte se convierte en mercancía es algo indudable. De hecho, sobre esta realidad gira todo el sistema del arte, pero es en ese "convertirse» donde reside la clave de este fenómeno. El arte se convierte en mercancía por medio de estas industrias (culturales) derivadas, pero no lo es en su origen. Este no es un aspecto en absoluto baladí, porque nos encontramos con que «948 Merkatua», uno de los eventos estrella dedicados a la cultura y el arte de Gobierno de Navarra, focaliza su atención en el mercado y su importancia, dejando fuera de foco el nivel anterior al de la industria: la creación. Sería interesante atender, además de al mercado, a las condiciones de trabajo de quienes propician este sector: los y las artistas. Mientras estos se muevan en la precariedad derivada de la práctica inexistencia de tejido artístico (encargos institucionales, premios y certámenes públicos con presupuestos para la producción y adquisición de obra, convocatorias que no escatimen en honorarios y gastos de taller, galerías, coleccionistas, etc.) será casi imposible su acceso como agentes solventes en escenarios competitivos como el que propicia «948 Merkatua", que «apuesta por la creación híbrida y los contenidos interdisciplinares, entendiendo que en la producción cultural de nuestros días, a través del diálogo entre disciplinas, se producen algunas de las más interesantes innovaciones creativas y culturales ${ }^{2}$. Desde el punto de vista de la creación artística última, lo más atractivo de este foro es la oportunidad que brinda a producciones de carácter performativo, escénico y audiovisual para su difusión (todas ellas manifestaciones fácilmente integrables dentro de las industrias culturales). Recordemos que en nuestra comunidad es prácticamente imposible disfrutar de este tipo de obras por la falta de equipamientos adecuados y de programas que propongan y hagan accesible al público general este tipo de trabajos. Sin embargo, ha sido notable la ausencia de propuestas plásticas, de invitados e invitadas que formalicen sus obras mediante disciplinas tales como fotografía, pintura, etc., realidad que en años anteriores sí tenía cabida. Volvemos a encontrarnos aquí con las consecuencias de mirar al arte exclusivamente desde la industria, como mercancía.

Como evento imprescindible para tomar la temperatura a la realidad artística en Navarra, pese a los cambios de formato y tratamiento del que ha sido objeto por parte de las instituciones implicadas, tenemos las muestras de la convocatoria de ayudas a las artes plásticas y visuales de Centro Huarte y Gobierno de Navarra del año 2018. Continuando con el formato que se le dio en 2016 bajo la nueva dirección del Centro

1 La UNESCO define el conjunto de las industrias culturales y las industrias creativas como «Aquellos sectores de actividad organizada que tienen como objeto principal la producción o la reproducción, la promoción, la difusión y/o la comercialización de bienes, servicios y actividades de contenido cultural, artístico o patrimonial» (http://www.unesco.org/new/es/culture/themes/cultural-diversity/diversity-of-\%09cultural-expressions/tools/policy-guide/como-usar-esta-guia/sobre-definiciones-\%09que-se-entiende-por-industrias-culturales-y-creativas/).

2 https://www.948merkatua.com/es/inicio 
de Arte Contemporáneo de Huarte (en adelante $\mathrm{CACH}$ ), pudimos asistir entre abril y mayo a "Habitación: Zazpi-Siete», dedicada a los proyectos beneficiarios de las citadas ayudas en su modalidad de producción. Una pequeña muestra de estos proyectos becados fue expuesta en el CACH, si bien este centro ya no es un lugar expositivo. Al hilo de la muestra, se ofreció al público, como es ya habitual, una sesión de mediación de los trabajos de Amaia Gracia Azqueta, Andrea Ganuza Santafé, David Mutiloa, Estitxu Arroyo Sánchez, Marisa Mantxola, Txuspo Poyo y Xabier Erkizia con una educadora ( «Akanpada»), un encuentro con uno de los artistas («Aperitifak», con Xabier Erkizia), y la que fue la más enriquecedora de las sesiones: el encuentro abierto al público entre los y las artistas y la curadora Maite Garbayo Maeztu. Califico este encuentro como el más enriquecedor de los celebrados por brindar la oportunidad a los propios creadores y creadoras de hablar de sus proyectos con una interlocutora experta y versada. En «Habitación» nunca accedemos a los proyectos completos sino a la selección de algunas de las piezas que los integran, por lo que acceder al discurso que los y las creadoras nos proponen con sus trabajos es extremadamente complicado. En este encuentro público, Garbayo mantuvo con cada artista una conversación bien fundamentada sobre cada uno de los proyectos, algo que verdaderamente resultó útil para contextualizar y comprender cada una de las propuestas.

Curiosamente, y por un breve lapso (entre el 31 de octubre y el 24 de noviembre), pudimos asistir a la exposición de estos proyectos, pero completos en esta ocasión, en la sala Muralla de Baluarte. Si bien las fechas de la muestra resultaron breves fue un acierto para su difusión hacerlas coincidir con la celebración de "948 Merkatua", ya que la complejidad de montar una exposición con obra de siete artistas es elevada (transportes, seguros, montaje, etc.). Y digo curiosamente por la infrautilización de esta sala en lo que concierne al arte. Ya sin apenas uso para producciones artísticas contemporáneas ${ }^{3}$, en ella se han programado durante este año exposiciones como la dedicada a los muñecos Click o "Expo-Wars». Me gustaría recordar que entre los años 2007 y 2009 tuvieron lugar en esta sala las exposiciones que formaron parte del programa «Punto de encuentro con el arte contemporáneo», impulsado por el Departamento de Cultura y Turismo-Institución Príncipe de Viana de Gobierno de Navarra. Este programa trató de acercar al público el arte contemporáneo de más reciente creación. En la Sala Muralla vimos: «Silencios. 22 pintores navarros», comisariada por Juan Manuel Bonet; «Markus Lüpertz. Cuerpo y Paisaje», comisariada por Kosme de Barañano; «Planes futuros: arte español de los 2000», comisariada por María de Corral y Lorena Martínez de Corral; y «La pintura española en los tiempos del Arte. Veinte pintores españoles para el siglo XXI», comisariada por Enrique Andrés Ruiz. Todas ellas contaron, además, con la edición de catálogo razonado, folleto de mano, textos explicativos en sala y conferencias públicas relacionadas. Considero especialmente relevante el intento de activación de esta sala por parte del CACH dada la falta de lugares que acojan proyectos expositivos de arte contemporáneo último. Pero lo que de veras sería importante

3 En esta sala pudimos ver en noviembre de 2018 dentro del marco de «948 Merkatua» la exposición «Únicas» de la fotógrafa navarra Cristina Núñez Baquedano, proyecto también producido por Gobierno de Navarra en su convocatoria de ayudas a las artes visuales, plásticas e innovación en 2016. 
es conseguir un compromiso firme y estable para el aprovechamiento de esta sala con exposiciones como esta, ya que desde que CHAC decidiera volcarse en los procesos de creación, las producciones completas resultantes de esta convocatoria de ayudas de Gobierno de Navarra no se han presentado al público de manera unificada. En la mayoría de los casos, cuando estos proyectos requieren de una formalización de tipo expositivo, ni tan siquiera se han presentado.

Fuera del circuito institucional encontramos Apaindu. Con una contrastada trayectoria dentro del mundo del diseño de interiores y la decoración, este espacio dirigido por Inazio Beloki se ha convertido en los últimos años en la única galería de Pamplona con un verdadero compromiso por el arte contemporáneo en Navarra. Demostrando un conocimiento amplio de nuestro contexto artístico, las exposiciones de Apaindu nos dan la oportunidad de conocer los últimos trabajos de artistas con trayectorias consolidadas y cuyas producciones son de difícil acceso en un momento en el que el criterio «joven» $y$ «emergente» priman en convocatorias y proyectos. Sin duda, los y las creadoras requieren de ayudas específicas en sus etapas iniciales para la consolidación de discursos y trayectorias, pero estas sirven de poco en una actividad en la que la profesionalización es casi imposible y la atención a los perfiles de media carrera no existe. Así pues, Apaindu cubre una necesidad que las distintas instituciones tienen todavía pendiente. Durante 2019 pudimos ver los trabajos de Jabier Villarreal, Xabier Idoate, Eugenio Ortiz Miguel, Dicky Rekalde, Jose Miguel Corral y Txaro Fontalba. Esta última presentó "Clitoria», amplio proyecto que gira en torno a la práctica de la mutilación genital femenina y que se vincula estrechamente con sus trabajos anteriores. Esta exposición presentó una iniciativa extraordinariamente interesante: se enmarcó en los cursos de formación para profesorado del CAP sobre arte y feminismo ${ }^{4}$ y fue, además, visitada por adolescentes de distintos institutos que realizaron trabajos curriculares a partir de la visita. Me resulta llamativo que exposiciones de instituciones públicas, que en principio deberían contar con más medios para la producción, difusión, mediación, etc., no ofrezcan, por lo general, algo tan básico a nivel de mediación y, un paso más allá, de generación de públicos. Tal vez se debería prestar más atención a lo que sucede en algunos lugares para tomar nota de cómo compartir el acto creativo, sus discursos y su trascendencia, a públicos no exclusivamente especializados, porque de lo contrario estamos desaprovechando el poder que tiene el arte como activador de conciencias y generador de una ciudadanía crítica y empática.

Un intento en ese sentido, de escucha, de atención para una toma de posiciones coherente y sensible a la situación del sector y su contexto, fueron «Fabular Hiriartea // Alegiazko Hiriartea» y «Pensar Hiriartea juntas», jornadas organizadas en el seno de Hiriartea, el que fuera el proyecto de Centro de Cultura Contemporánea de Pamplona dependiente del Ayuntamiento de Pamplona. En la primera de estas jornadas se invitó a la comunidad artística de la ciudad (artistas y profesionales del sector, asociaciones, etc.) a debatir y realizar diversas aportaciones para dilucidar de forma compartida

4 Curso en el CAP Pamplona en 2019: «Arte feminista: Conciencia, militancia y debate en la producción artística contemporánea». 
cómo sería un centro de cultura contemporánea idóneo para la ciudad. El encuentro se inició con una toma de contacto con el espacio de la Ciudadela, sus infraestructuras y particularidades en forma de paseo comentado a cargo del equipo directivo y técnico del Área de Cultura y Educación del Ayuntamiento de Pamplona. Le siguió un café-tertulia entre Arantza Santesteban, coordinadora de Hiriartea, y la comisaria e investigadora experta en modelos de gestión sostenibles en el mundo del arte y la cultura contemporánea, Haizea Barcenilla. Para finalizar, se empleó una metodología activa que ayudara a formalizar las ideas y aportaciones de todas las personas participantes en esta jornada. Así, mediante tres talleres simultáneos dirigidos por tres artistas de diferentes ámbitos, se manifestaron y recogieron las necesidades y deseos de un sector habitualmente olvidado en los procesos de definición y toma de decisiones.

Dos meses después de este encuentro llegó «Pensar juntas Hiriartea», jornada abierta de devolución de las conclusiones obtenidas en los talleres, donde poder hablar a partir de lo detectado en las conclusiones, del futuro de Hiriartea como espacio en el que poner en relación las prácticas artísticas y el pensamiento contemporáneo.

De nada servirá lo recogido en esas jornadas. La Ciudadela no contempla ya ese fabulado Centro de Cultura Contemporánea de Pamplona al haber sido cesada su coordinadora y cancelado el proyecto. Hiriartea, si bien ha resultado confuso en sus dos primeros y únicos años de vida (ha contado desde su inicio con muy importantes hándicaps estructurales y presupuestarios; ni más ni menos que hacer frente a una correcta adecuación y accesibilización de sus espacios, protegidos por ser edificios patrimoniales), también ha presentado propuestas aperturistas y ambiciosas con las que sí ha cumplido sus objetivos previos de ofrecer un espacio abierto de encuentro, de disfrute y de conocimiento, inspirado en iniciativas y experiencias de creación a través de la exhibición, el encuentro ciudadano y la creación. Cabe señalar las originales propuestas de mediación en forma de visita experimental a la exposición "Abstraktu! Abstracciones en la Colección de Arte Contemporáneo del Ayuntamiento de Pamplona», a cargo de la bailarina y coreógrafa Ghislaine Verano, y del colectivo Zuzuzu, o a la exposición «Axerizulo» de Santos Bregaña por el cineasta Óscar Alegría, y el escritor Harkaitz Cano. Destacable también, y acorde con el interés de Hiriartea por la accesibilización y el acercamiento al público de los contenidos del arte contemporáneo último, la jornada dedicada específicamente a la mediación cultual desarrollada en el Palacio del Condestable en la que se debatió con expertas locales y nacionales pertenecientes a ámbitos académicos, asociativos y museísticos, acerca de qué es la mediación, qué ideas residen en su base y cómo pueden materializarse en la práctica.

Una verdadera lástima haber prescindido de este proyecto a la mitad de su desarrollo, cuando empezaba a demostrar una entidad propia y a presentar propuestas con afán de continuidad y comprometidas con el contexto artístico local en su sentido más amplio (creación, mediación, públicos), a través de prácticas ya establecidas como habituales en los centros de arte a nivel nacional, y no simples eventos desconectados de un todo mayor que finalmente tan solo sirven para rellenar agendas. Mucho me temo que el contexto local saldrá gravemente perjudicado con este cambio si la propuesta de sustitución para Hiriartea prescinde del arte como motor principal de acción. Si el 
arte pierde el pequeño espacio que tradicionalmente ha tenido en la ciudad, nos encontraremos con una Pamplona culturalmente inerte, carente de lugares para el arte con el negativo impacto que eso conlleva a nivel de ciudadanía y salud democrática. Pienso firmemente que la cultura debe ser ajena a legislaturas y vaivenes políticos o de lo contario nunca dejaremos de padecer los efectos perjudiciales de políticas culturales erráticas que empeoran las condiciones de todas y todos, no solo de quienes se dedican profesionalmente a este sector. Es importante no olvidar que la cultura y el arte no son cuestiones accesorias ni carentes de sentido, sino aspectos esenciales equiparables al progreso científico para nuestro pleno desarrollo como sociedades, y así se recoge en la Declaración Universal de Derechos Humanos, ${ }^{5}$ donde encontramos una importante referencia a los Derechos culturales en su artículo 27.

Otra actividad dependiente del Área de Cultura del Ayuntamiento de Pamplona cuya continuidad es dudosa es la muestra de videoarte "Otras luces-Bestelako argiak». El comisariado artístico de la cuarta edición de la muestra volvió a recaer en el alumnado de la Elías Querejeta Zine Eskola y contó con los artistas navarros Amaia Gracia Azqueta e Iker Serrano para su mediación en forma de visitas acompañadas, como ya se hiciera en la edición de 2018. Repitiendo el éxito de respuesta y participación de públicos del año pasado, esta experiencia de mediación se revela como una actividad imprescindible para el acceso conceptual a las obras de videoarte programadas. No por mostrarse en lugares públicos y a la vista de todas y todas estas creaciones son evidentes en sus mensajes, intenciones y lecturas. Bienvenidas son todas las propuestas que nos hagan partícipes, acerquen e introduzcan en los códigos altamente codificados de las prácticas artísticas contemporáneas. Por otra parte, y dentro de este mismo programa, nos encontramos con la reedición en los jardines de la Ciudadela de la pieza interactiva «Tökkö», así como en los dos túneles de acceso la instalación «Köppö». Y no puedo evitar preguntarme por qué se opta por la reedición y no por el encargo de obra nueva. No olvidemos que entre los compromisos del Área de Cultura del Ayuntamiento de Pamplona está promover el incremento del patrimonio artístico del Ayuntamiento y esta sería una buena ocasión para invertir en nuevos fondos para la colección. Apostar por la adquisición de obra también sería beneficioso para dar aire a las exposiciones colectivas que en los últimos años se vienen realizando con los fondos de la colección del Ayuntamiento y que empiezan a resultar repetitivas en sus selecciones.

No quiero dejar de hablar de "Mapamundistas», iniciativa ya consolidada por su coherencia y calidad. El proyecto que la comisaria Alexandra Baurès desarrolla cada año, no solamente en Pamplona sino en diferentes municipios, es un perfecto ejemplo de trabajo comisarial. A través de la Asociación Cultural La Caracola y contando con el patrocinio de Gobierno de Navarra y Ayuntamiento de Pamplona, así como con la participación de otras entidades tanto públicas como privadas entre las que se cuentan el Institut Français y el Goethe Institut, Baurès vuelve a materializar con éxito un pro-

5 Declaración Universal de Derechos Humanos de 10 de diciembre de 1948, aprobada por la Asamblea General de las Naciones Unidas: «1. Toda persona tiene derecho a tomar parte libremente en la vida cultural de la comunidad, gozar de las artes y participar en el progreso científico y en los beneficios que de él resulten». 
yecto complejo en el que dentro del comisariado introduce esta vez la producción artística. Este año, y teniendo la película Zerkalo del cineasta ruso Andrei Tarkovski como desencadenante, «Mapamundistas», con sus exposiciones, proyecciones y encuentros, nos proponía un ejercicio de introspección. Como podíamos leer en el texto curatorial de la propia Alexandra Baurès: «las obras de arte constituyen una colección de espejos en los que las experiencias estéticas provocadas por otros pueden revertir en nuestro propio ser». Así, y continuando con el espíritu de su edición anterior, Baurès nos ofreció cinco exposiciones individuales ${ }^{6}$ en Ciudadela, un ciclo de cine de autor en Civivox Iturrama, un taller de fotografía en Museo de Navarra, visitas guiadas a las exposiciones para el alumnado de centros de educación primaria y secundaria en distintos idiomas y dos jornadas de encuentros con los artistas. Todas ellas actividades orientadas a «la contemplación honda de lo que somos, como individuos y comunidad» a través del arte y sus posibilidades.

Repasando las exposiciones y eventos de nueva creación, dedicaré unas líneas a «A la mesa», propuesta itinerante comisariada por María Ozcoidi. Primera de «Uholdeak», nuevo programa expositivo de carácter anual para la difusión del arte contemporáneo en Navarra, es el fruto de la colaboración entre el CHAC, Fundación Caja Navarra, Fundación Obra Social «La Caixa» y las casas de cultura de Aoiz, Tudela, Alsasua y Tafalla. Si bien la exposición no resultó especialmente innovadora en cuanto a diseño expositivo o postulados (cuestiones como territorio o identidad dan vida al grueso de producciones artísticas de unos años a esta parte), resulta relevante por atender a la necesidad de exponer las obras y proyectos que los y las artistas producen en CHAC y que han ido quedando pendientes de formalización y presentación pública. La exposición además contó con un recurso para la mediación destinado al trabajo en aula de docentes y alumnado diseñado por el equipo del CHAC. Producción artística local, exhibición y mediación son tres ejes esenciales en los que se integran de manera orgánica los diferentes agentes del sector artístico incluyendo a los públicos, y si además se articulan en torno a una propuesta no solo planteada para Pamplona, sino que atiende a más localidades, estamos ante una apuesta que se perfila como un verdadero ejemplo de acción artística en Navarra. Como digo, este programa que considero tan pertinente en el momento actual del arte en la Comunidad Foral se concibe con intención anual, sin embargo, me pregunto en qué medida tendrán continuidad los proyectos que actualmente se desarrollan en CHAC (este entre ellos) ya que este año toca decidir si se renueva o no su actual dirección. Insisto en la importancia de dar tiempo para el desarrollo y asentamiento de planes rectores en instituciones dedicadas a la cultura y arte contemporáneos. Es vital entender que estos requieren de un margen para su implementación pues es preciso hacer diagnósticos y valoraciones profesionales para llegar a diseñar e implementar programas eficientes, eficaces y que respondan a las necesidades reales de un contexto tan complejo y largamente desatendido como el que nos ocupa. Si nos in-

6 Concha Martínez Barreto (Dibujo. 1. a planta del Pabellón de Mixtos, Ciudadela), Andrés Galeano (Archivo fotográfico. Edificio El Sario, UPNA) Roger Omar (Trabajos propios y realizados por los escolares participantes en el taller de ilustración de sueños desarrollado en varios colegios cercanos al Batán de Villava. Batán, Villava), Julie Chaffort (Videocreación. 1. a planta del Pabellón de Mixtos, Ciudadela), y Javier Arbizu (Escultura. Residencia en CHAC y exposición en la sala Horno, Ciudadela). 
clinamos por gestiones breves nunca llegaremos a ver resultados solventes porque estos requieren de tiempo de maduración y consolidación.

También en 2019 tuvo lugar un evento importante para la Comunidad Foral: la reapertura del Museo de Navarra. Bajo el lema «Todo el arte es contemporáneo», el Museo «busca adaptarse al tiempo actual y a la nueva forma de disfrutar del arte que demandan visitantes y audiencias. [...] se quiere dar el salto al siglo XXI, haciendo especial hincapié en el arte contemporáneo» ${ }^{7}$. Según nos dice el propio Museo, asistimos a su mayor reforma en los últimos treinta años. Además de la renovación de elementos de fachada y vestíbulo, se ha adecuado la capilla anexa como sede de exposiciones temporales de artistas navarros vivos con obra en los fondos de la institución ${ }^{8}$. La remusealización, si bien es cierto que se hace notar en todas las salas a través de un nuevo discurso y planteamiento museológico, se centra en las plantas $3 .^{\mathrm{a}}$ y $4 .^{\mathrm{a}}$. En ellas el habitual orden cronológico ha sido sustituido por uno más ambicioso y acorde a las derivas museográficas actuales. Se ha recurrido a una pauta conceptual que muestre cómo interpretan artistas y obras preocupaciones fundamentales de la humanidad como la espiritualidad y la permanencia, lo social o lo femenino. Esta nueva ordenación ha implicado una profunda revisión tanto de los fondos como de la exposición permanente del Museo, labor ya iniciada en 2016 con el proyecto crítico «Reflexión/Inflexión: presencia de las mujeres en el Museo de Navarra». De este modo, se ha dado importancia a la obra de artistas navarros del XIX y XX y, por supuesto, se ha recuperado el trabajo de las artistas, cuyas obras han quedado tradicionalmente relegadas a los fondos y olvidadas. Contextualizar las obras sin atender exclusivamente a su cronología, sino observando relaciones de sentido internas, enriquece la experiencia de quienes visiten la exposición, ya que facilita la integración de las obras en un contexto de experiencias y saberes mayor, más accesible y relacionado con vivencias y conocimientos propios. Esta integración de las obras en un todo mayor se ve reforzada por la línea cronológica que recibe al público en la 4. a planta y que abarca desde el siglo XIX hasta la actualidad. En ella encontramos una selección de hitos sociales y culturales, donde el desempeño de las mujeres cobra una especial relevancia, que nos ayuda a situarnos en el contexto histórico de las obras expuestas. Con un imprescindible trabajo de mediación en sala, diseñado por el Grupo Edarte de la Universidad Pública de Navarra, así como con la elaboración de una guía de lectura fácil, la apuesta por la modernización y adecuación al nuevo perfil de los públicos es evidente. Con un total de setenta y una nuevas obras expuestas, tres itinerarios guiados, una sala destinada exclusivamente a exposiciones temporales de fotografía, nueva señalética y dispositivos de mediación en sala, obras contemporáneas que dialogan con obras de otros periodos en diferentes salas, y la convivencia de distintas disciplinas (pintura, fotografía, grabado, cartelería, música, cine documental, escultura), el compromiso de renovación del Museo de Navarra queda de manifiesto. Conocer las necesidades y deseos del contexto en el que una institución se enclava y relacionarse con ellos ofreciendo contenidos y propuestas de calidad que los contemple es clave para su

7 http://www.culturanavarra.es/es/todo-el-arte-es-contemporaneo

8 Por el momento, desde su inauguración hemos podido ver las exposiciones «Inspiración, Espiración, Expiación», de la artista alsasuarra Dora Salazar y «Extemporáneo», del artista pamplonés Carlos Irijalba. 
integración real en el territorio y con la ciudadanía. Tan solo quedarían pendientes dos cuestiones. Por un lado, una sistematización de la oferta de mediación profesional en sala para las exposiciones temporales. Iniciativa exitosa en anteriores encuentros como, por ejemplo, las visitas razonadas a las exposiciones «Lydia Anoz. Los años dorados 1945-1956» y «Lydia Anoz. Hacia la luz y hacia la vida. Décadas 1970 y 1980» a cargo de su comisaria, Celia Martín Larumbe. Por otro, su implicación activa en la creación de obra nueva que incremente el patrimonio navarro, ya que entre sus objetivos está el de acrecentar los bienes de nuestro patrimonio como comunidad.

Para concluir este repaso, hablaré de «Suero», un proyecto de carácter efímero en Pamplona que ha mantenido su continuidad de forma virtual en redes sociales. «Suero» es una iniciativa de la curadora y artista limeña Luisa Fernanda Lindo, quien a lo largo de su estancia en Pamplona durante 2019, propiciada por su participación en la 1. ${ }^{a}$ edición del máster Curatorial Studies de la Universidad de Navarra, desarrolló en paralelo un proyecto personal independiente y autofinanciado para la reflexión, creación y exhibición de arte contemporáneo. Como la propia Lindo explica: “Suero" es un proyecto curatorial nacido con la voluntad de generar un espacio de diálogo e intercambio en torno a la creación artística y problemáticas sociales, culturales, políticas y económicas, así como para abordar la misma práctica artística y sus procesos de creación, producción y difusión» ${ }^{9}$. Impresiona la capacidad de agencia de Lindo, quien, sin disponer de apoyos institucionales ni económicos, ni de una red sólida de contactos en la ciudad, fue capaz de llevar a cabo una serie de encuentros de interés y calidad notables sin ningún tipo de respaldo más allá del de los y las artistas invitadas. De espíritu similar a «Salón», creado en Madrid por la artista Ángela Cuadra, Lindo organizó en el salón de su propio apartamento una primera jornada en marzo. En ella asistimos a «Todos los espacios están comprendidos en mi reino» de la artista chilena Claudia Coca, quien tras su paso por ARCO Madrid mostró en Pamplona una selección de obra reciente. En mayo, los invitados a la segunda jornada de «Suero» titulada «La arbitrariedad de los códigos» fueron Miguel Orcal (Lima) y Ana García-Pineda (Sabadell) con producciones audiovisuales y performáticas. Por último, en la tercera y última jornada en Pamplona, «Suero» abandonó el espacio doméstico para trasladarse al Casco Viejo de Pamplona. En esta ocasión, y bajo el título «Mudanza», doce artistas de España y Perú con la característica común de residir fuera de sus lugares de origen fueron invitados a reflexionar con imágenes de obra ya producida en torno al concepto de mudanza. Esta reflexión coincidía con la llevada a cabo por la curadora, quien emprendía su propio proceso de mudanza a Latinoamérica. «Suero» continúa activo con exposiciones virtuales a través de su cuenta en Instagram.

Este último evento expositivo nos sitúa cara a cara con el fenómeno de la precarización de los trabajos en arte. Especialmente en los de creación e investigación. El voluntarismo no debería tener lugar en ningún sector profesional. De hecho, nos resulta impensable imaginarlo en otros ámbitos, sin embargo, en este que nos ocupa es una realidad cotidiana aceptada y participada por casi toda persona implicada. En este 
repaso he hablado de eventos dedicados al mercado y a las industrias creativas y culturales, exposiciones de carácter institucional, públicas, privadas, particulares, etc. Todos ellos construidos sobre una estructura extremadamente frágil. Nos encontramos con un panorama en el que abunda la etiqueta de «emergente». No es de extrañar, conforme artistas y profesionales del comisariado y la investigación en arte van cumpliendo años su acceso a concursos y convocatorias se ve restringido, cuando no imposibilitado, y como consecuencia de la ausencia de un tejido en el que desarrollarse, estas figuras devienen invisibles y acaban por desvanecerse. En un contexto como el navarro en el que no se ha conseguido crear un tejido bien entrelazado de colaboraciones interinstitucionales y de participación mixta, resultado de la falta de compromisos sólidos y duraderos, así como de la desconfianza en los diferentes proyectos puestos en marcha por las distintas administraciones a lo largo de los años, es una misión de solución difícil conseguir un sector funcional y solvente. Por el momento, estamos lejos de saber aprovechar y sacar el máximo rendimiento a todo su potencial que, como hemos visto a lo largo de este artículo, no es poco. Un buen principio sería atender a las condiciones en las que actualmente se trabaja en las primeras y más esenciales fases del universo de la creación para proponer una adecuada sistematización de recursos beneficiosa para todo el sector al completo.

Como decía al principio de este artículo, si tras la recesión que siguió a la crisis económica mundial de 2008, y de la que el mundo de la cultura aún se resiente ${ }^{10}$, la ayuda de los gobiernos se centró prioritariamente en el rescate de los grandes bancos y empresas privadas para evitar lo que se vaticinaba como el desplome definitivo del sistema financiero, de nuevo veremos cómo las medidas económicas que se adopten determinarán, ya no el futuro, sino el presente de este sector tan precarizado. Y si observamos más de cerca, veremos el impacto que tendrá sobre los y las artistas (estas últimas especialmente vulnerables dentro de los vulnerables) ${ }^{11}$.

Considero necesario para comprender el calado de esta nueva crisis desencadenada por las consecuencias del COVID-19 conocer algunos datos que clarifiquen lo que el mundo de la cultura supone dentro de nuestro tejido productivo. Tradicionalmente pensamos que el trabajo en el ámbito del arte y la cultura se asemeja a estereotipos establecidos a partir de la fama de grandes personalidades cuyas condiciones rara vez se replican en los estratos cotidianos que conforman dicho sector. El cultural es un sector que, lejos también de la bohemia y el diletantismo que legendariamente tienden a caracterizarle, sucede gracias al trabajo y capacitación de muy diversos perfiles laborales y profesionales. Si consultamos los datos de la Encuesta de Población Activa (EPA) presentados por el Anuario de Estadísticas Culturales de $2018^{12}$ estamos hablando de

10 Recordemos que algunas de las medidas de impacto negativo en el sector del arte y la cultura consecuencia de esta crisis fueron, entre otras, la supresión en 2012 del Ministerio de Cultura, pasando a ser Ministerio de Educación, Cultura y Deporte, o la subida del IVA cultural del $8 \%$ al $21 \%$.

11 https://mav.org.es/

12 Ministerio de Cultura y Deportes. (2018). Anuario de Estadísticas Culturales 2018. Madrid. Disponible en http://www.culturaydeporte.gob.es/dam/jcr:f818fa71-6313-468b-9db1-6a44d4fbd461/principales-resultados-2018.pdf 
687200 trabajadores y trabajadoras. Esta cifra supone un 3,7\% del empleo regulado en nuestro país. Un porcentaje aparentemente reducido pero esencial, ya que el cultural es un sector clave en términos de influencia social y creación de imaginarios colectivos.

Como ya ha declarado la Mesa Sectorial del Arte Contemporáneo ${ }^{13}$, para este sector la situación ocasionada por la pandemia es de extrema gravedad por la cancelación de exposiciones en galerías, museos, centros de arte y espacios culturales diversos tanto nacionales como internacionales; la suspensión de actividades de formación, mediación y divulgación; la interrupción en la venta de obras y encargos de distinta naturaleza (restauración, producción, conservación, etc.); la paralización de las residencias para la creación artística, los programas de investigación y creación dependientes tanto de subvenciones públicas como de instituciones y organismos privados. Señala también como esta situación se agrava más en el caso de las mujeres, pues como en toda crisis, y como consecuencia de su permanente situación de desigualdad, soportan las peores condiciones del sistema productivo y cargan con el peso de los cuidados propios del ámbito reproductivo.

Podría hablar del arte y la cultura como la más potente herramienta de proyección exterior de comunidades y países, también como importante generadora de empleo en un país volcado en el turismo, pero voy a incidir especialmente en su dimensión como indicador decisivo de salud democrática, de ciudadanía formada, crítica y moralmente comprometida y proactiva.

Como posible punto de partida para el desarrollo de una política cultural eficaz y eficiente que afronte en nuestra comunidad las dificultades en las que estamos inmersos, sería interesante redefinir el concepto "cultura» (término que de tan manido ha terminado por devenir escurridizo en su significado y alcances) atendiendo a su doble función social: la cultura como derecho, algo recogido ya en nuestra propia Constitución, ${ }^{14}$ y la cultura como recurso económico. Entender esta doble vertiente y desarrollarla de manera conjunta y coherente, así como plantear las diferencias conceptuales y funcionales entre políticas culturales públicas y políticas industriales para la cultura, podría ser un buen principio para construir una estrategia duradera y bien fundamentada que propicie la atención correcta y posibilite el máximo desarrollo de un sector altamente cualificado en la Comunidad Foral. 